\title{
Handheld laser devices and laser-induced retinopathy (LIR) in children: an overview of the literature
}

\author{
James E. Neffendorf ${ }^{1} \cdot$ G. Darius Hildebrand ${ }^{1}$. Susan M. Downes ${ }^{1}$
}

Received: 28 April 2018 / Revised: 18 December 2018 / Accepted: 20 February 2019 / Published online: 20 March 2019

(c) The Royal College of Ophthalmologists 2019

\begin{abstract}
Handheld laser devices are easily available to purchase through the internet and unregulated marketplaces at a relatively low cost. They are particularly attractive to children as they are seen as 'high tech', brightly coloured, and known to be able to burn holes in objects such as balloons. There is a widespread lack of knowledge about the risks of viewing the beam emanating directly from handheld lasers, and particularly those with high-output powers. The number of reported laser induced retinopathy (LIR) injuries in children is on the increase in the United Kingdom and represents a major public health issue. The number of individuals affected by LIR is likely to be underestimated owing to lack of presentation to health professionals, general poor awareness and non-reporting by children after the incident. The presentation of LIR is highly variable and dependent on many factors including type of laser, length of exposure and how it is administered. In this article, we review the features of retinal damage associated with inadvertent or deliberate laser administration using a handheld laser device. We highlight the importance of educating the wider public about this increasing problem; children who play with these devices are usually completely unaware of the long-term consequences of laser damage to the eye. It is also important that the features of LIR are recognised by health professionals involved in eye care as they can be mistaken for retinal dystrophies, particularly if the history of laser exposure is not volunteered or elicited.
\end{abstract}

\section{Introduction}

The use of laser devices has become ubiquitous in everyday life. Their introduction has led to significant technological advances since their discovery in the 1960s with use in medicine, industry and research. They are also utilised widely as teaching aids in the form of laser pointers. However, as with many useful technologies, if used incorrectly they can pose a significant health hazard.

Despite a normal blink and aversion reflex of $\sim 0.2 \mathrm{sec}$, high-powered lasers have the potential to irreversibly damage the eye, which can result in bilateral central visual acuity loss. The anatomy of the eye is set up to focus on a bright point of light, thus the fovea, the area of the retina which subserves fine detailed vision, is particularly vulnerable to a burn from a laser. Central retina is primarily

Susan M. Downes

susan.downes@ouh.nhs.uk

1 The Oxford Eye Hospital, John Radcliffe Hospital, Oxford OX3 9DU, UK affected and therefore reading and driving vision may be affected causing significant visual disability with a lifelong impact.

There has been significant media interest in handheld laser devices recently. Concerns have been raised about the potentially catastrophic effect these devices may have on aviation, with reports of lasers being shone directly at airline pilots. Although these types of laser strikes on aircraft have not been shown to result in permanent visual or retinal structural defects, they are of significant concern because they can cause severe glare and temporary flash blindness. Regulatory bodies are currently examining legislation to reduce the risk of a catastrophic airline incident [1].

\section{How are lasers classified?}

In the 1970s, a classification system based on output power was implemented to address safety issues in laser use, and guide regulation in the UK and USA [2,3]. (Table 1) At that time, those belonging to class IIIb and class IV with an output power above $5 \mathrm{~mW}$ were considered to be potentially damaging to the eye, if viewed directly. A revised system of 
Table 1 Laser hazard classification based on power emission

\begin{tabular}{lll}
\hline Class of laser & Output power & Potential risk \\
\hline I & Very low & Nil \\
II & $<1 \mathrm{~mW}$ & Safe by blinking reflex \\
IIIa & $<5 \mathrm{~mW}$ & May be dangerous if used with optical instruments \\
IIIb & $5-500 \mathrm{~mW}$ & Can cause damage if beam enters eye (even for short duration, c. 0.01 s) \\
IV & $>500 \mathrm{~mW}$ & High power, may cause severe eye damage \\
\hline
\end{tabular}

Laser classification system, determined by output power [2, 3] classifying lasers based on improved scientific knowledge was introduced in the mid 2000s by the International Electrochemical Commission (IEC) and incorporated into the American National Standards Institute (ANSI) laser safety standards [4]. Only lasers up to $5 \mathrm{~mW}$ (Class $3 \mathrm{R}$ ) with a visible wavelength between 400 and $700 \mathrm{~nm}$ can now be legally sold in the United States (Table 2). In the United Kingdom, toy lasers for children should be Class 1 or below according to Public Health England Guidance [5]. Class $3 \mathrm{R}$ lasers $(<5 \mathrm{~mW}$ output power) are also legally able to be sold in the UK because they are useful for specific purposes, for example in the building industry.

However, class 4 lasers have an important therapeutic role in eye disease. Their use is wide ranging from treating skin lesions, thickened posterior capsules, and glaucoma to diseases of the posterior segment such as diabetic retinopathy, retinal vein occlusions and rarer vascular anomalies. Ocular tissues respond differently to lasers of various wavelengths, and laser users must be knowledgeable about the different laser types and their therapeutic indications. In addition, the user must be aware of the relevant protective eyewear for the specific wavelength of the laser for those in its vicinity. Laser use is carefully regulated locally with laser protection and safety protocols in place with representative officers in each ophthalmology department and in each NHS Hospital Trust. They are responsible for ensuring that induction for laser users is completed, covering core knowledge, clinical guidelines and implementation of local protocols with formal accreditation before use of the device by appropriate accredited users.

\section{Lasers for use in posterior segment disease}

One of the principal treatments for proliferative diabetic retinopathy is pan-retinal photocoagulation using a photothermal laser such as a frequency-doubled nd-YAG $532 \mathrm{~nm}$ or yellow $577 \mathrm{~nm}$ laser. Frequency-doubled nd-YAG lasers deliver energy which is absorbed primarily by melanin present in the retinal pigment epithelium (RPE) and choroid, resulting in heat induced photoreceptor coagulation and scar formation [6]. The longer wavelength of yellow lasers enables improved penetration through dense ocular media with less light scattering. Their energy is absorbed both by melanin and oxyhaemoglobin in the blood (which has an absorption peak at $577 \mathrm{~nm}$ ), resulting in reduced thermal spread with a potentially lower required power to achieve a similar burn to that of a $532 \mathrm{~nm}$ laser. The effect of scarring and increased retinal adhesive force can also be used to seal off peripheral retinal breaks; research has shown that the adhesive force triples two weeks after the procedure, substantially reducing the occurrence of an associated retinal detachment [7].

Photothermal lasers are also often used in the treatment of clinically significant macular oedema in diabetic patients, via multiple potential mechanisms of action. Microaneurysm photocoagulation resulting in microaneurysm occlusion is considered to reduce leakage, and other proposed theories include improved oxygen diffusion to the inner retina resulting in reduced hypoxia due to the scarring, in turn leading to autoregulatory vasoconstriction and thus improvement in macular oedema [8-10]. There is also some evidence that when laser energy is absorbed by damaged RPE, adjacent healthy RPE cells may proliferate and replace damaged cells at the macula, releasing chemomodulatory agents such as TGF- $\beta$ which antagonise the effects of VEGF and therefore improve diabetic macular oedema [11, 12].

The subthreshold micropulse lasers $(810 \mathrm{~nm}$ diode and $577 \mathrm{~nm}$ yellow) were introduced in an attempt to reduce laser thermal damage to the macula [13]. Energy is delivered in microsecond bursts of repetitive short pulses which induce thermal stress on RPE cells, but with a heat rise that the cells can withstand and thus apoptosis is avoided. No scar formation occurs with these lasers, and the long 'off' time of these lasers between pulses allows heat dissipation to prevent collateral retinal damage. Also re-treatment can be performed. Research is ongoing to fully understand the benefit of this technology in macular disease and the optimal wavelength. Diode lasers penetrate deeper into the choroid, potentially minimising damage to the inner neurosensory retina [14]. Yellow lasers are minimally absorbed by macular xanthophyll pigment, which is advantageous in enabling treatment close to the fovea [15]. 


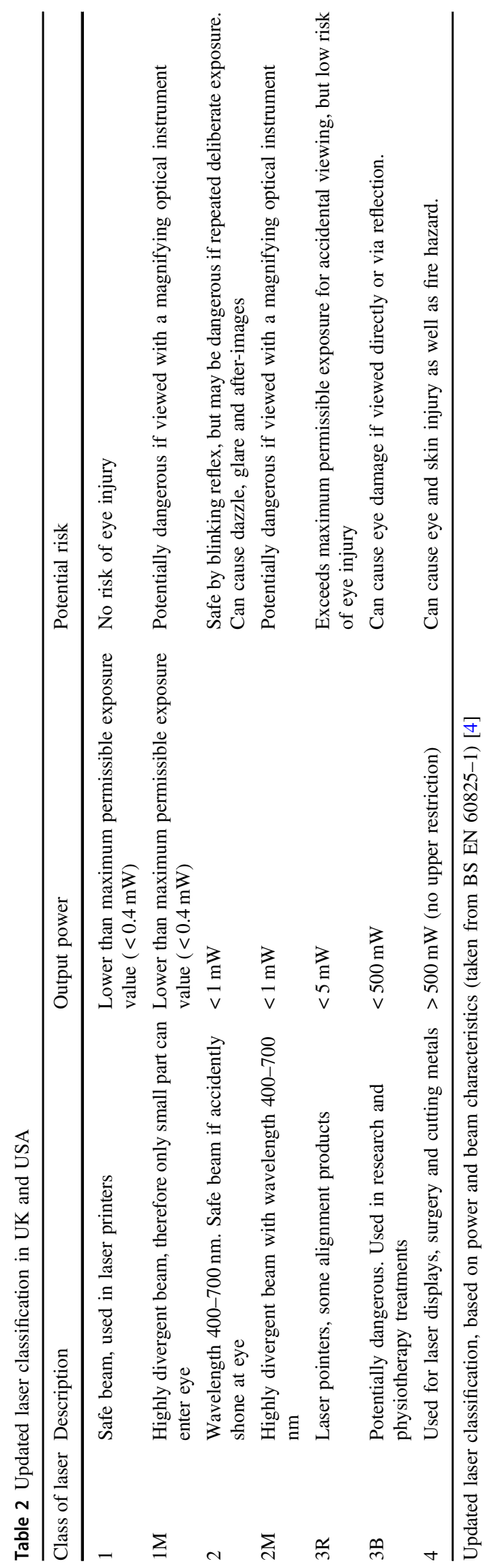

\section{Lasers for anterior segment and skin}

Lasers have a considerable role in the management of glaucoma. Laser trabeculoplasty can be used to increase the conventional aqueous outflow route through the trabecular meshwork (TM) by increasing circumferential traction on the TM [16]. At first, this procedure was performed using an argon laser targeting the TM, but more recently, selective laser trabeculoplasty (SLT) using a frequency-doubled nd-YAG $532 \mathrm{~nm}$ laser to specifically target pigmented TM cells has been introduced $[17,18]$. The SLT process uses a very short pulse duration meaning the energy delivered is insufficient to result in conversion to thermal energy and therefore less heat is generated with no collateral damage to adjacent tissue [19].

Another indication for laser intervention in glaucoma includes the treatment of angle closure or prophylactic treatment to potentially occludable drainage angles, by creating a laser iridotomy using a nd-YAG laser. The 1064 nm YAG laser is used to photo-ionise and disrupt the target iris tissue creating a hole for aqueous humour to circulate freely [20]. The same lasers can be focussed on the posterior lens capsule to treat posterior capsular opacification following cataract surgery [21].

Diode lasers, with a wavelength of $805-810 \mathrm{~nm}$ are well absorbed by melanin pigment in the eye, and therefore may be used to treat the ciliary body in some patients with high intra-ocular pressure by cyclodestruction [22]. This procedure has traditionally been utilised in refractory end-stage glaucoma, but is now gaining popularity at an earlier stage both in adults and in paediatric glaucoma. The mechanisms of action proposed include ciliary epithelial destruction, resulting in reduced aqueous production, ciliary body ischaemia secondary to coagulative necrosis and increased uveo-scleral outflow [16].

Finally, infrared erbium:YAG lasers $(2940 \mathrm{~nm})$ and carbon dioxide lasers $(10600 \mathrm{~nm})$ can be focussed on skin cells and scars around the eye in resurfacing procedures [23]. Carbon dioxide lasers cause more coagulative thermal damage than erbium:YAG lasers which are strongly absorbed by water, and therefore selectively destroy diseased (low water content) areas such as scars. Both lasers are effective and well tolerated [23].

\section{Laser pointers and laser-induced retinopathy (LIR)}

In the 1990s, there was widespread media interest regarding laser pointers used in lectures in the education sector, and whether they could cause ocular injury. This news coverage led to a large increase in eye casualty attendances [24]. However, at that time it was considered that these laser 
pointers did not pose a significant risk to ocular tissues [25, 26]. In 1999, the first case report of a 34-year-old male deliberately staring at a $5 \mathrm{~mW}$ laser was published [27, 28]. Clinical examination of this case revealed disturbance at the level of the RPE and fundus fluorescein angiography revealed a window defect at the macula. However as the visual acuity measured 20/20 snellen, and on the basis that a previous animal study had shown $5 \mathrm{~min}$ exposure of a 5 $\mathrm{mW}$ laser to not be harmful to the retina, doubt was cast on whether the anatomical defect in this case was indeed due to the laser [29].

Subsequently, a prospective telephone study investigating any reported visual symptoms in 14 patients with a history of sustaining laser burns (mean follow-up interval of 10 months) reported no subjective visual loss [30]. However, by 1998 it was already well known that laser-induced maculopathy could easily result from industrial or military accidents [26, 31].

Since those first reports, far more powerful handheld devices have become available (including those up to 1200 $\mathrm{mW}$ ) and may be bought over the internet and from unregulated sellers, despite the introduction of UK regulation (BS EN 60825-1:2014). They are relatively cheap and easy to buy online and attractive to teenagers and young children owing to their bright appearance, moving light properties, and that they can burn holes in objects. They come in different colours, most commonly red and green. (Fig. 1) Furthermore, enticing slogans such as 'the best light sabres you can buy' are used to boost their popularity.

A case report of a 15-year-old boy, who sustained lifechanging retinal laser burns, highlights the attraction of these devices to this age group, who are unaware of the associated risks to vision. The laser pointer was bought initially to pop balloons, but during his attempts to create a light show, using a mirror and the laser pointer, he sustained several direct hits to his retinas [32]. Concerned about the potential public health risk, the FDA released guidance in 2014 about the danger of lasers to children, and in 2017 published an article with an educational video on the risks of laser pointers [33, 34].
Recently, in our department we have seen children who have retinal features consistent with LIR. This probably represents an underestimate of the actual numbers affected, owing to the possible reluctance of a child to admit usage, and retinal features that mimic other conditions in the context of low suspicion of this potential aetiology by the health-care professional, as well as misdiagnosis owing to unrecognised features. The Journal of Paediatrics published an article saying this was an emerging public health issue and that paediatricians and ophthalmologists must be vigilent [35].

\section{How do lasers damage the eye?}

The nature in which lasers cause their effects in the eye can be photocoagulative, photodisruptive or by photochemical mechanisms. If sufficient energy reaches the retina in under a nanosecond, then ionisation is the mechanism. Durations of microseconds to a few seconds results in thermal damage, and a duration over $10 \mathrm{sec}$ results in photochemical effects. The degree of LIR depends on the wavelength, output power, duration of application and direction of focus.

The type and degree of LIR will also depend on the specific wavelength of the laser device. Long wavelength red lasers cause thermal damage to the eye. Green lasers cause energy to be delivered to the melanin pigment in the $\mathrm{RPE}$ at a wavelength of $532 \mathrm{~nm}$ and therefore result in RPE and outer retinal damage. If a shorter wavelength green laser or shorter still blue laser is viewed, more energy is delivered to the eye causing photochemical damage. It is important to note that some green and blue lasers may also emit infrared wavelength energy [36]. Handheld lasers, depending on the wavelength and duration, can lead acutely to retinal blanching or a more severe burn resulting in a laser scar. The long-term effect on visual function will depend not only on the above, but the manner in which the laser is delivered. For example, in the case of deliberate administration the duration may be long, not confined to the fovea alone and be extensive in deliberate self harm. Thus,
Fig. 1 Example of red and green handheld lasers, being scattered by liquid nitrogen
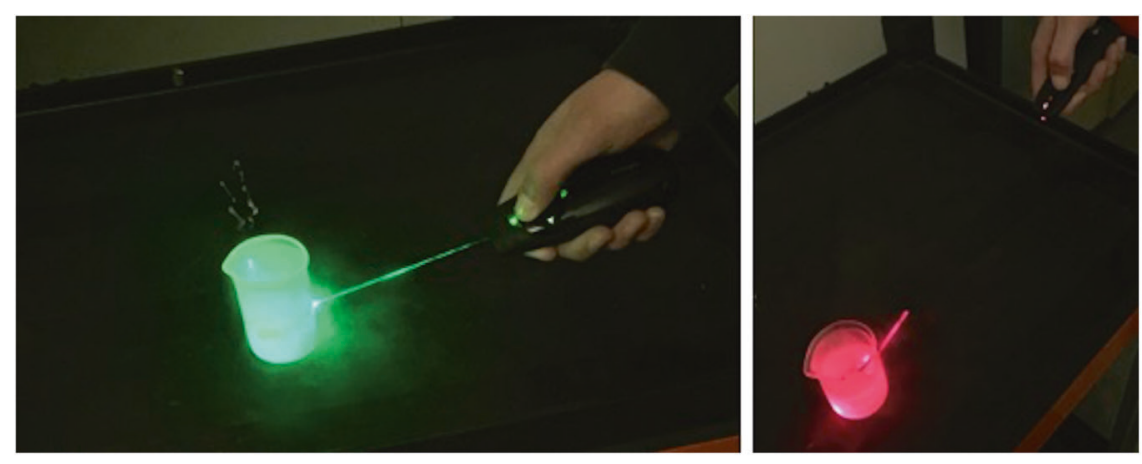
the sequelae can vary from severe significant reduction in visual acuity, to no obvious clinical impact [37, 38].

\section{How do laser injuries present?}

The presentation of handheld laser injuries in the paediatric population can be quite variable. Children are often difficult historians, and additionally, they may delay reporting visual problems to parents owing to feelings of guilt after playing with these apparent toys. Alternatively, laser scars may be noted at a routine visit to the Optometrist. It is therefore often difficult to ascertain the exact time of the injury and the chronicity of any maculopathy. A good history is important using a gentle, probing approach, and should include the exclusion of a potential history of unprotected eclipse watching or sungazing, which may have given rise to features of solar retinopathy, which mimic those of LIR.

An example case was a 14-year-old boy who was referred to our department with macular changes following a routine visit to his optician. On careful questioning, he admitted to previously playing with lasers. Fundal examination revealed macular scarring and inner segment-outer segment (IS-OS) junction retinal disruption on optical coherence tomography (OCT) (Fig. 2). His best corrected visual acuity (BCVA) at presentation measured 6/7.5 snellen in the right eye, which improved to $6 / 6$ snellen at 9 months follow-up. At 9 months, the clinical findings show subtle retinal remodelling without treatment (Fig. 2).

As would be expected owing to the variety of laser pointers available and variability in mechanism of injury (duration and position of use), a wide spectrum of injury severity may be observed. A systematic review has shown the BCVA at initial presentation was less than 20/40 snellen in $55 \%$ of affected eyes, $20 / 20$ or better in $9 \%$ of affected eyes, and in some cases was substantially reduced to counting fingers [39]. It has been suggested that mild injuries tend to be unilateral and may clinically appear as vitelliformlike lesions or resemble an inherited macular dystrophy, whereas more severe injuries may result in large atrophic retinal scars [30, 31]. Table 3 summarises case reports and series, worldwide, of all reported handheld laser injuries to children between 1999 and 2017 [30, 32, 35, 38-57]. (Table 3)

One case series of 11 patients with LIR due to blue wavelength laser, who were all reported to have developed macular holes, did not specify the mechanism of injury for each individual. However, all were inflicted by others during play, except one case which was self-inflicted [43]. A UK 16 child case series was excluded from this review as details about individual patients were not described [37]. However, the authors reported injuries varying from mild IS-OS disruption to severe hyper-reflective material in the inner retinal layers with significant visual loss, which is in keeping with other reports [37].

Raoof et al. [37] provide a classification of retinal laser injuries based on their OCT appearance to quantify RPE laser energy absorption and overlying retinal damage. Despite classifying whether the injury is classified as 'mild', 'moderate' or 'severe' based on OCT appearance, it has been difficult to correlate these injuries with the degree of visual impairment or prognosis [37]. Table 4 shows the variation in types of retinal damage observed in all reported cases. (Table 4) Variation from mild RPE change, to vitelliformlike lesions, haemorrhages and macular hole formation have been documented. Similarly, the OCT appearance
Fig. 2 Fundus photography and optical coherence tomography (OCT) of a 14-year old child with laser-induced retinopathy. a Fundus photography of the right eye at presentation revealing macular scarring. b OCT of the right eye at presentation showing inner segment-outer segment junction disruption. $\mathbf{c}$ and $\mathbf{d}$ Fundus photography and OCT of the right eye at 9 months follow-up showing subtle retinal remodelling
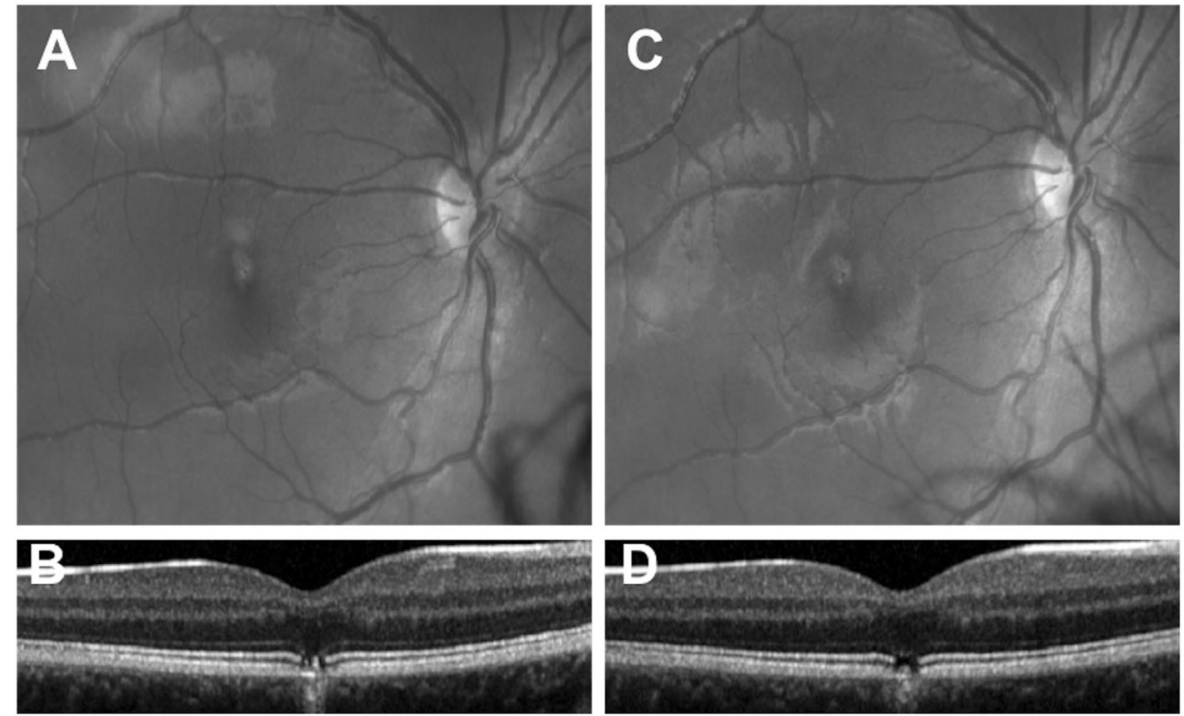


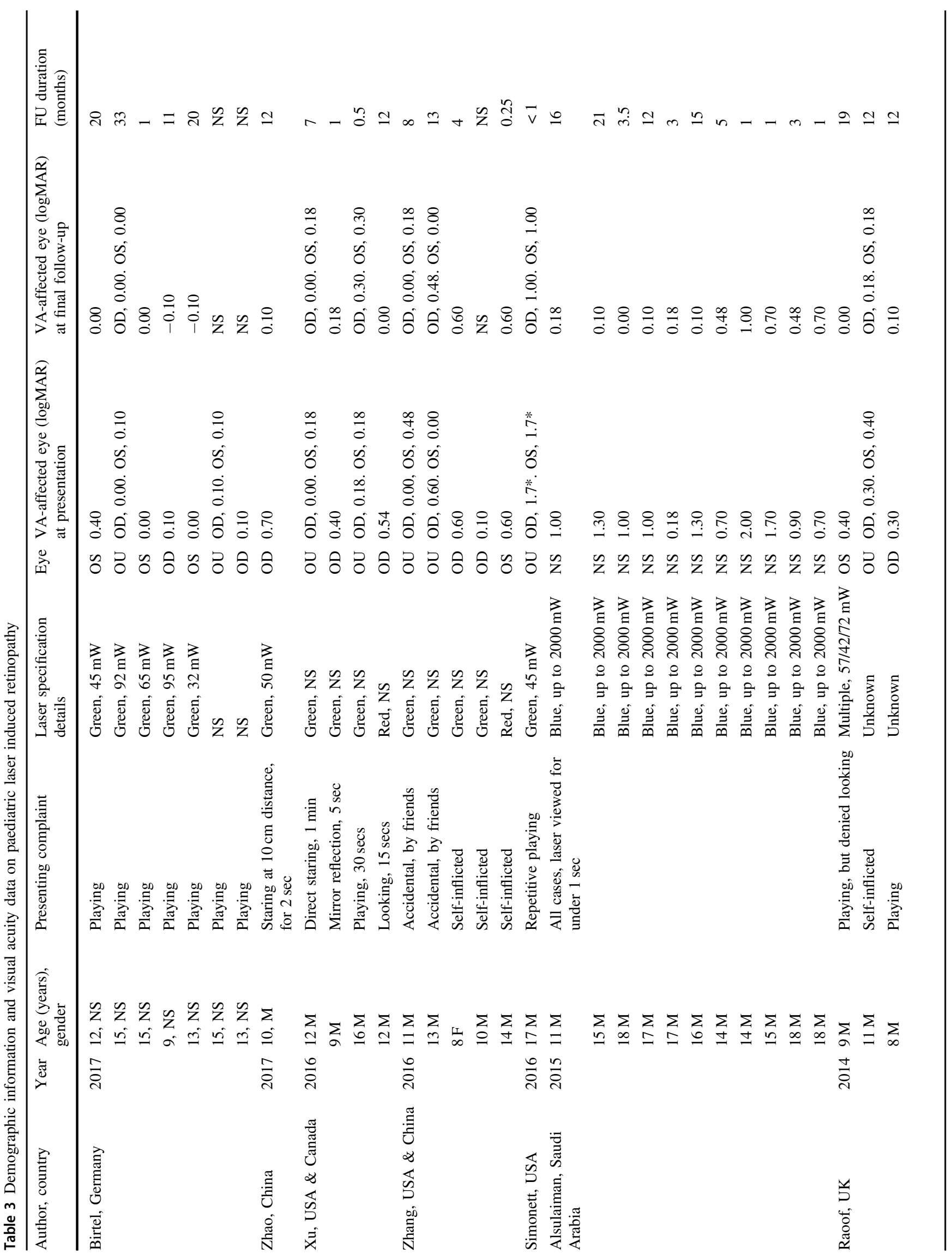




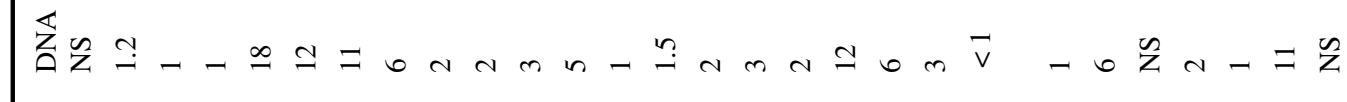

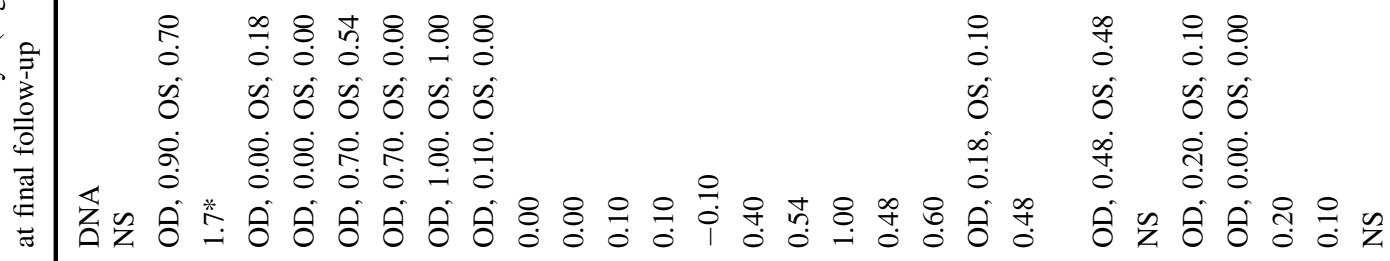

$\widehat{\overbrace{}}$

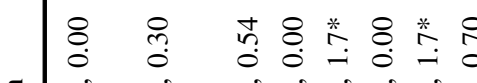

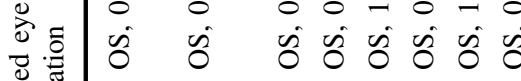

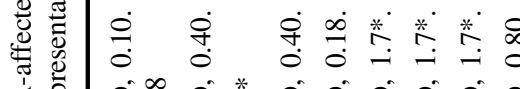

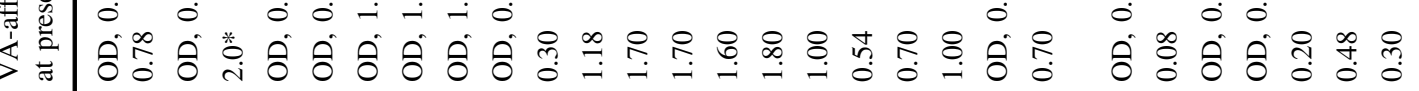

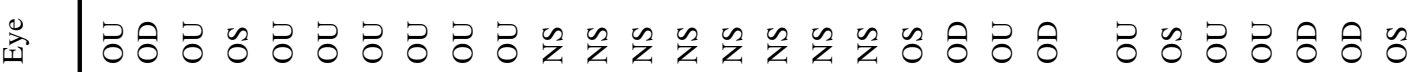

音

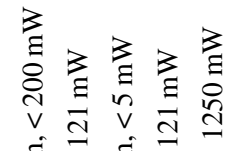

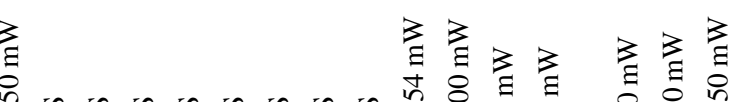

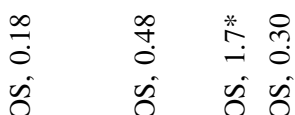

की की की की

守 过 守腺

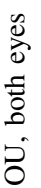
.

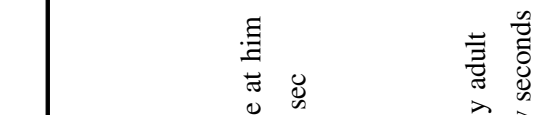

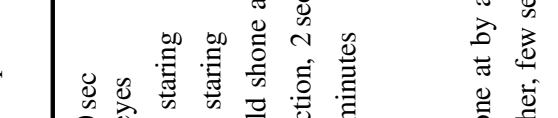

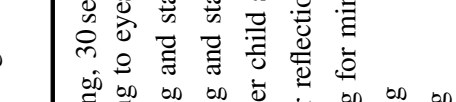

亳:

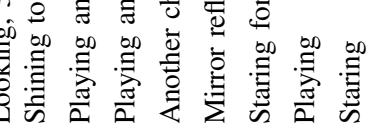

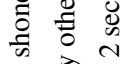

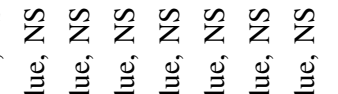

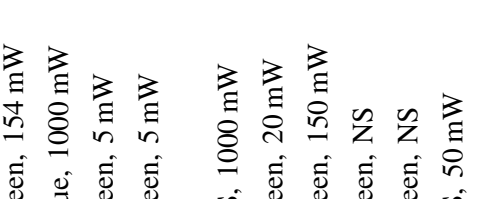

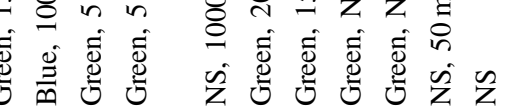
(1)

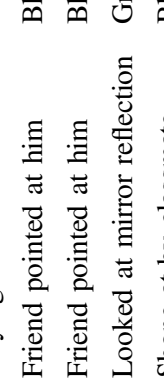

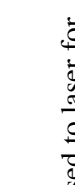

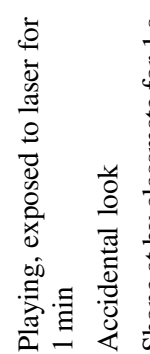

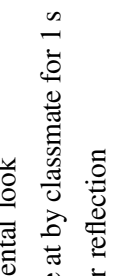

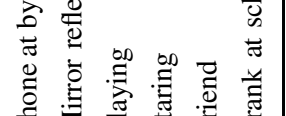

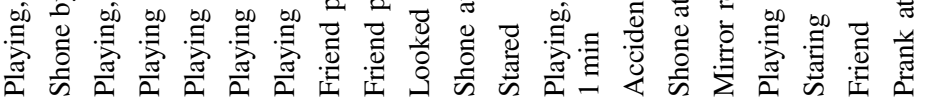

(2)

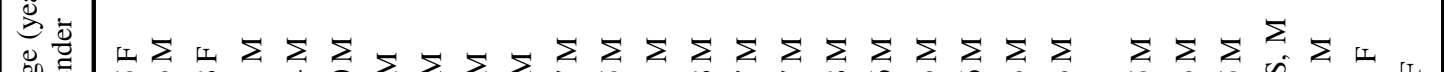

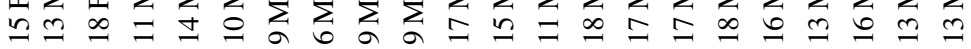

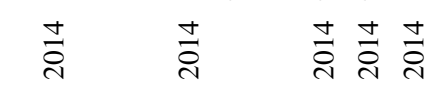

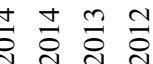

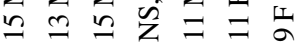

密

兽

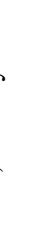
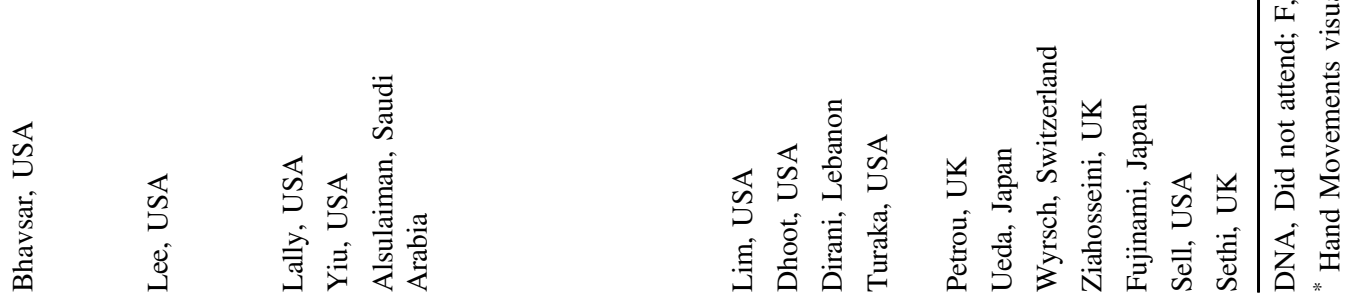
Table 4 Clinical and optical coherence tomography characteristics of children suffering laser induced retinopathy

\begin{tabular}{|c|c|c|c|c|}
\hline Author, country & Year & $\begin{array}{l}\text { Age (years), } \\
\text { gender }\end{array}$ & Fundal findings & OCT changes \\
\hline \multirow[t]{7}{*}{ Birtel, Germany } & \multirow[t]{7}{*}{2017} & $12, \mathrm{NS}$ & Yellow lesion, pigment changes & Intraretinal fluid \\
\hline & & $15, \mathrm{NS}$ & Yellow lesion, pigment changes & Structural loss of outer retina \\
\hline & & $15, \mathrm{NS}$ & Pigment changes & Structural loss of outer retina \\
\hline & & $9, \mathrm{NS}$ & NS & Structural loss of outer retina \\
\hline & & $13, \mathrm{NS}$ & NS & Structural loss of outer retina \\
\hline & & $15, \mathrm{NS}$ & Pigment changes & Structural loss of outer retina \\
\hline & & $13, \mathrm{NS}$ & Pigment changes & Structural loss of outer retina \\
\hline Zhao, China & 2017 & $10, \mathrm{M}$ & Altered foveal reflex & $\begin{array}{l}\text { Sub-foveal disruption to RPE and IS-OS } \\
\text { junction }\end{array}$ \\
\hline \multirow[t]{4}{*}{$\mathrm{Xu}$, USA \& Canada } & \multirow[t]{4}{*}{2016} & $12 \mathrm{M}$ & Pigment clumping and RPE atrophy & IS-OS junction disruption \\
\hline & & $9 \mathrm{M}$ & Macular pigment changes & $\begin{array}{l}\text { Outer retinal and photoreceptor } \\
\text { hyper-reflectivity }\end{array}$ \\
\hline & & $16 \mathrm{M}$ & Macular chorioretinal scars and RPE atrophy & IS-OS junction disruption \\
\hline & & $12 \mathrm{M}$ & $\mathrm{RPE}$ atrophy, CNV and haemorrhage & NS \\
\hline \multirow[t]{5}{*}{ Zhang, USA \& China } & \multirow[t]{5}{*}{2016} & $11 \mathrm{M}$ & Foveal dendritic pattern & $\begin{array}{l}\text { IS-OS, interdigitation zone and RPE } \\
\text { disruption }\end{array}$ \\
\hline & & $13 \mathrm{M}$ & Foveal dendritic pattern & $\begin{array}{l}\text { IS-OS, interdigitation zone and RPE } \\
\text { disruption }\end{array}$ \\
\hline & & $8 \mathrm{~F}$ & Foveal dendritic pattern & $\begin{array}{l}\text { IS-OS, interdigitation zone and RPE } \\
\text { disruption }\end{array}$ \\
\hline & & $10 \mathrm{M}$ & Foveal dendritic pattern & $\begin{array}{l}\text { IS-OS, interdigitation zone and RPE } \\
\text { disruption }\end{array}$ \\
\hline & & $14 \mathrm{M}$ & Foveal dendritic pattern & $\begin{array}{l}\text { IS-OS, interdigitation zone and RPE } \\
\text { disruption }\end{array}$ \\
\hline Simonett, USA & 2016 & $17 \mathrm{M}$ & Bull's eye foveal appearance & $\begin{array}{l}\text { IS-OS junction disruption. Right eye - } \\
\text { macular hole }\end{array}$ \\
\hline \multirow{11}{*}{$\begin{array}{l}\text { Alsulaiman, Saudi } \\
\text { Arabia }\end{array}$} & \multirow[t]{11}{*}{2015} & $11 \mathrm{M}$ & Macula hole with faint whitening at base & FTMH \\
\hline & & $15 \mathrm{M}$ & Macula hole with faint whitening at base & FTMH \\
\hline & & $18 \mathrm{M}$ & Macula hole with faint whitening at base & FTMH \\
\hline & & $17 \mathrm{M}$ & Macula hole with faint whitening at base & FTMH \\
\hline & & $17 \mathrm{M}$ & Macula hole with faint whitening at base & FTMH \\
\hline & & $16 \mathrm{M}$ & Macula hole with faint whitening at base & FTMH \\
\hline & & $14 \mathrm{M}$ & Macula hole with faint whitening at base & FTMH \\
\hline & & $14 \mathrm{M}$ & Macula hole with faint whitening at base & FTMH \\
\hline & & $15 \mathrm{M}$ & Macula hole with faint whitening at base & FTMH \\
\hline & & $18 \mathrm{M}$ & Macula hole with faint whitening at base & FTMH \\
\hline & & $18 \mathrm{M}$ & Macula hole with faint whitening at base & FTMH \\
\hline \multirow[t]{5}{*}{ Raoof, UK } & \multirow[t]{5}{*}{2014} & $9 \mathrm{M}$ & Vitelliform-like maculopathy & $\begin{array}{l}\text { Hyper-reflective columns from RPE to } \\
\text { outer retina }\end{array}$ \\
\hline & & $11 \mathrm{M}$ & Yellow macular lesions & Hyper-reflectivity in outer retinal layers \\
\hline & & $8 \mathrm{M}$ & Foveal RPE changes & Disruption of outer retinal bands \\
\hline & & $15 \mathrm{~F}$ & Vitelliform-like maculopathy & NS \\
\hline & & $13 \mathrm{M}$ & Fibrosed CNV & NS \\
\hline \multirow[t]{3}{*}{ Bhavsar, USA } & \multirow[t]{3}{*}{2014} & $18 \mathrm{~F}$ & RPE changes & $\begin{array}{l}\text { Ellipsoid zone disruption and } \\
\text { hyper-reflective bands }\end{array}$ \\
\hline & & $11 \mathrm{M}$ & Deep yellow foveal lesion with white streaks & $\begin{array}{l}\text { Ellipsoid zone disruption and } \\
\text { hyper-reflective bands }\end{array}$ \\
\hline & & $14 \mathrm{M}$ & Perifoveal RPE changes & Ellipsoid zone disruption \\
\hline
\end{tabular}


Table 4 (continued)

\begin{tabular}{|c|c|c|c|c|}
\hline Author, country & Year & $\begin{array}{l}\text { Age (years), } \\
\text { gender }\end{array}$ & Fundal findings & OCT changes \\
\hline \multirow[t]{3}{*}{ Lee, USA } & \multirow[t]{3}{*}{2014} & $10 \mathrm{M}$ & $\begin{array}{l}\text { Pigment clumping circled by } \\
\text { hypo-pigmentation }\end{array}$ & Juxtafoveal hyper-reflective mound \\
\hline & & $9 \mathrm{M}$ & Flat yellow lesions with RPE disruption & $\begin{array}{l}\text { Hyper-reflective column and hypo- } \\
\text { reflective cavity }\end{array}$ \\
\hline & & $6 \mathrm{M}$ & Flat yellow lesion with radiating streaks & Hyper-reflective mound \\
\hline Lally, USA & 2014 & $9 \mathrm{M}$ & Yellow-green foveal lesion with spokes & $\begin{array}{l}\text { Vertical outer retinal hyper-reflective } \\
\text { column }\end{array}$ \\
\hline Yiu, USA & 2014 & $9 \mathrm{M}$ & Pre-retinal haemorrhage & Sub-hyaloid haemorrhage \\
\hline \multirow{8}{*}{$\begin{array}{l}\text { Alsulaiman, Saudi } \\
\text { Arabia }\end{array}$} & \multirow[t]{8}{*}{2014} & $17 \mathrm{M}$ & Outer retinal yellow-orange discolouration & IS-OS junction disruption \\
\hline & & $15 \mathrm{M}$ & Sub-ILM haemorrhage & Sub-ILM haemorrhage \\
\hline & & $11 \mathrm{M}$ & Sub-hyaloid haemorrhage & NS \\
\hline & & $18 \mathrm{M}$ & Sub-hyaloid haemorrhage & NS \\
\hline & & $17 \mathrm{M}$ & Sub-hyaloid haemorrhage & NS \\
\hline & & $17 \mathrm{M}$ & Sub-hyaloid haemorrhage & NS \\
\hline & & $18 \mathrm{M}$ & Epiretinal membrane and macular thickening & $\begin{array}{l}\text { Thick epiretinal membrane and foveal } \\
\text { detachment }\end{array}$ \\
\hline & & $16 \mathrm{M}$ & Dull foveal reflex & Schisis like cavity with sub-retinal fluid \\
\hline Lim, USA & 2014 & $13 \mathrm{M}$ & Hypo-pigmented RPE & Focal disruption and RPE atrophy \\
\hline Dhoot, USA & 2014 & $16 \mathrm{M}$ & $\begin{array}{l}\text { Central hypo-pigmentation surrounded by } \\
\text { hyper-pigmentation }\end{array}$ & Small macular hole \\
\hline Dirani, Lebanon & 2013 & $13 \mathrm{M}$ & $\begin{array}{l}\text { Yellow drusenoid lesions and altered light } \\
\text { reflex }\end{array}$ & $\begin{array}{l}\text { Disrupted outer retinal layers and } \\
\text { thickening }\end{array}$ \\
\hline Turaka, USA & 2012 & $13 \mathrm{M}$ & Greyish foveal lesion & RPE disruption and retinal thickening \\
\hline Petrou, UK & 2012 & $15 \mathrm{M}$ & Macular Hole & Macular Hole \\
\hline Ueda, Japan & 2011 & $13 \mathrm{M}$ & Central hypopigmented spot & $\begin{array}{l}\text { IS-OS junction disruption and } \\
\text { hyperreflective column }\end{array}$ \\
\hline Wyrsch, Switzerland & 2010 & $15 \mathrm{M}$ & RPE scars and dense sub-retinal haemorrhage & NS \\
\hline Ziahosseini, UK & 2010 & NS, M & Foveal granularity & RPE disturbance \\
\hline Fujinami, Japan & 2010 & $11 \mathrm{M}$ & Yellow lesion and sub-retinal haemorrhage & Highly reflective outer retinal/RPE mass \\
\hline Sell, USA & 1999 & $11 \mathrm{~F}$ & Pigment clumping and loss of light reflex & NS \\
\hline Sethi, UK & 1999 & $9 \mathrm{~F}$ & NS & NS \\
\hline
\end{tabular}

CNV, Choroidal neovascularisation; F, female; FTMH, Full thickness macula hole; ILM, Internal limiting membrane; IS-OS, inner segment-outer segment; M, male; NS, not specified; OCT, optical coherence tomography; RPE, retinal pigment epithelium; VL, vision loss

from presumed laser damage ranges from IS-OS junction disruption to hyper-reflective outer retinal column appearances. OCT imaging is crucial in this group of patients, because the true effect of the laser may not be visible on slit lamp examination alone [44].

It is important to note that there are many differential diagnoses with imaging that can resemble the injuries seen with handheld lasers. These include inherited conditions such as Best disease, cone-rod dystrophies and Stargardt disease. A careful history is of key importance and in patients with these specific features a high suspicion of potential LIR should be entertained. Indeed, some patients have been found to have LIR after being referred for genetic work-up for possible inherited retinal disease [37-39].

\section{Treatment of LIR}

There is no recognised treatment for LIR, and most are diagnosed at some time after the event. In general, visual acuity tends to improve naturally over time following LIR, although permanent visual loss and scotomata can occur $[35,38,39,50]$. Some groups have used topical or systemic corticosteroids, on the basis that they reduce release of the cytokine cascade and inhibit RPE cell proliferation with improvement reported in some cases [46, 49, 58, 59]. A case report of a 25 -year old patient treated with oral corticosteroids after laser pointer induced maculopathy described the reversal of outer retinal hyper-reflective changes after one week of treatment [58]. It is difficult to ascertain whether visual improvement was owing to the steroid or the 
natural history of the injury and retinal remodelling. In addition, the risks and benefits of oral steroid use in this population especially when given at high dose need to be considered. Evidence for their use, and window of intervention is not yet known in LIR [60].

Oral lutein has been tried for LIR because of its antioxidant and anti-inflammatory effects as well as its protective role in other macular diseases [61]. Zhao et al. [41] showed a modest improvement in visual acuity after treatment with $20 \mathrm{mg}$ lutein for 12 months. However, this was a single case report with no control group and therefore whether the improvement can be attributed to the drug or spontaneous improvement is unknown. In addition, longterm safety data on this microsupplement in children would require further investigation.

Surgery for laser induced injuries such as full thickness macular hole and pre-macular sub-hyaloid haemorrhage with a pars plana vitrectomy, internal limiting membrane peel and neodymium:ytrium-aluminium-garnet laser hyaloidotomy respectively have been reported with good outcomes [43, 44].

At present, medical intervention for LIR is limited and the evidence for this is not available. A study on the timing, relative safety, efficacy and dosing of steroid would be helpful in guiding future management.

\section{Discussion}

Handheld laser retinal injuries are becoming more frequent, which is reflected in the media, ophthalmic literature and in clinical practice. In 2013, a UK survey of ophthalmologists returned 159 incidents of LIR, mostly in young children [62]. Despite more legislation, the easy availability of 'toy' lasers on the internet is increasing, resulting in dangerous strength lasers being accidentally used by children who are unaware of their potential risks. Of particular concern, one study has shown that these lasers often have incorrectly labelled or lack of information about their power [39]. In the UK, current legislation dictates that only safe lasers $(<5 \mathrm{~mW})$ should be made available to the public via general sale [62]. It is an offence for manufacturers to market or sell dangerous laser pointers. Regarding the aviation industry: 1500 laser attacks on aircraft per year have been reported since 2010. The Department of Transport has estimated a Boeing 747 crash with $100 \%$ fatalities would cost $£ 1.1 \mathrm{bn}$ when statistical value of life and damage costs are included [62].

Given the destructive nature of LIR, and lack of treatment options, visual outcome depends on whether both eyes are affected, the extent of the injury and scar progression. For this reason, the main priority should be prevention and this would be effected by widespread educational programmes involving schools, parents and carers as well as the media. Limitations on advertising of these devices and restriction by age should be implemented. It is also important to highlight LIR in the Optometry and Ophthalmic communities to improve diagnostic accuracy.

It is a key step that the UK government have recognised this developing public health issue, and recently released a call for evidence document precipitated by the increasing number of reported incidents of paediatric LIR and laser strikes on airline pilots [60]. The aim of this consultation is to establish whether tighter legislation, which may involve advertising restriction or ownership control as well as raised awareness, will bring about a reduction in these. Restriction will need to be appropriate and tailored towards protecting these particular groups so that the benefit of safe laser use is not affected. Professions that require ease of access to laser pointers include building surveyors (for measuring purposes), airport and agricultural staff (for scaring away stray birds) and sailors (for visual distress signals) as well as for teaching and training purposes. In other countries (e.g., New Zealand, Australia, Canada, Sweden, USA), licensing is in place to control handheld laser pointers, targeted at manufacturers, importers and consumers [62].

As ophthalmologists, we support the move by paediatricians to inform their specialty of the inherent risk of laser pointers [35]. Alongside governmental involvement, the royal colleges of Paediatrics and Ophthalmology have key roles in highlighting the problem to their members. It is also important for primary care services (general practitioners and high street optometrists) to identify cases of LIR, all of which require onward referral to ophthalmology departments. Detection requires directed and sensitive history taking as well as high-quality diagnostic methods.

For accurate diagnosis and subsequent follow-up, the use of indirect ophthalmoscopy and OCT are required, and classification systems have already been proposed [37]. Although ophthalmologists must be aware that current classifications cannot be used to predict outcome. Other imaging modalities including infrared photography and fundus autofluorescence are helpful in characterising LIR. By making an accurate diagnosis of LIR, pathology such as solar maculopathy and inherited retinal diseases can be excluded, which has important implications for families and for follow-up reviews [37, 38].

In conclusion, handheld laser pointers have the potential to cause life-changing retinal injuries in the individual as well as catastrophic loss of life when they are directed towards aircraft. We would like to encourage increasing awareness and tighter legislation to combat this emerging public health issue.

Acknowledgements We thank Mark Mackenzie and Fiona Thorburn (Institute of Photonics and Quantum Sciences, Heriot Watt University, Edinburgh) for providing the photographs of the red and green lasers. 


\section{Compliance with ethical standards}

Conflict of interest The authors declare that they have no conflict of interest.

Publisher's note: Springer Nature remains neutral with regard to jurisdictional claims in published maps and institutional affiliations.

\section{References}

1. Civil Aviation Authority. Lasers, our safety plan. https://www.caa. co.uk/Safety-initiatives-and-resources/How-we-regulate/Safety-Plan/ Mitigating-key-safety-risks/Lasers/. Accessed February 28, 2018.

2. (1992) BSEN 60825: 992. Radiation safety of laser products, equipment, classification, requirements and users guide. London: British Standards Institution; 1992.

3. American National Standards Institute (1993). American National Standard for the safe use of lasers, ANSI Z136.1. New York: National Standards Institute; 1993.

4. Safety of laser products - Part 1: Equipment classification and requirements (2nd edn). International Electrotechnical Commission. 2007.

5. Guidance - Laser radiation: safety advice. Public Health England. 2014.

6. Bressler NM, Beck RW, Ferris FL 3rd. Panretinal photocoagulation for proliferative diabetic retinopathy. N Engl J Med. 2011;365: 1520-6.

7. Yoon YH, Marmor MF. Rapid enhancement of retinal adhesion by laser photocoagulation. Ophthalmology. 1988;95:1385-8.

8. Romero-Aroca P, Reyes-Torres J, Baget-Bernaldiz M, BlascoSune C. Laser treatment for diabetic macular edema in the $21^{\text {st }}$ century. Curr Diabetes Rev. 2014;10:100-12.

9. Stefansson E. The therapeutic effects of retinal laser treatment and vitrectomy. A theory based on oxygen and vascular physiology. Acta Ophthalmol Scand. 2001;79:435-40.

10. Gottfredsdottir MS, Stefansson E, Jonasson F, Gislason I. Retinal vasoconstriction after laser treatment for diabetic macular edema. Am J Ophthalmol. 1993;115:64-7.

11. Glaser BM, Campochiaro PA, Davis JLJ, Jerdan JA. Retinal pigment epithelial cells release inhibitors of neovascularization. Ophthalmology. 1987;94:780-4.

12. Matsumoto M, Yoshimura N, Honda Y. Increased production of transforming growth factor-beta 2 from cultured human retinal pigment epithelial cells by photocoagulation. Invest Ophthalmol Vis Sci. 1994;35:4245-52.

13. Scholz P, Altay L, Fauser S. A review of subthreshold micropulse laser for treatment of macular disorders. Adv Ther. 2017;34:1528-55.

14. McHugh D, Marshall J, Ffytche TJ, Hamilton PA, Raven A. Diode laser trabeculoplasty (DLT) for primary open-angle glaucoma and ocular hypertension. Br J Ophthalmol. 1990;74: 743-7.

15. Mainster MA. Wavelength selection in macular photocoagulation. Tissue optics, thermal effects, and laser systems. Ophthalmology. 1986;93:952-8.

16. Kumar H, Mansoori T, Warji GB, Somarajan BI, Bandil S, Gupta V. Lasers in glaucoma. Indian J Ophthalmol. 2018;66:1539-53.

17. Wise JB, Witter SL. Argon laser therapy for open-angle glaucoma. A pilot study. Arch Ophthalmol. 1979;97:319-22.

18. Latina MA, Sibayan SA, Shin DH, Noecker RJ, Marcellino G. Qswitched 532-nm Nd:YAG laser trabeculoplasty (selective laser trabeculoplasy): a multicentre, pilot, clinical study. Ophthalmology. 1998;105:2082-8.
19. Latina MA, Park C. Selective targeting of trabecular meshwork cells: in vitro studies of pulsed and CW laser interactions. Exp Eye Res. 1995;60:358-71.

20. Saw SM, Gazzard G, Friedman DS. Interventions for angleclosure glaucoma: an evidence-based update. Ophthalmology. 2003;110:1869-78.

21. Aslam TM, Devlin H, Dhillon B. Use of Nd:YAG laser capsulotomy. Surv Ophthalmol. 2003;48:594-612.

22. Vernon SA, Koppens JM, Menon GJ, Negi AK. Diode laser cycloablation in adult glaucoma: long-term results of a standard protocol and review of current literature. Clin Exp Ophthalmol. 2006;34:411-20.

23. Chen KH, Tam KW, Chen IF, Huang SK, Tzeng PC, Wang HJ, et al. A systematic review of comparative studies of $\mathrm{CO} 2$ and erbium:YAG lasers in resurfacing facial rhytides (wrinkles). J Cosmet Laser Ther. 2017;19:199-204.

24. Syal R. Lasers are robbers' latest weapon. Sunday Times July. 1997:13:10.

25. Marshall J. The safety of laser pointers: myths and realities. Br J Ophthalmol. 1998;82:1335-8.

26. Mensah E, Vafidis G, Marshall J. Laser pointers: the facts, media hype, and hysteria. Lancet. 1998;351:1291.

27. Luttrull JK, Hallisey J. Laser pointer-induced macular injury. Am J Ophthalmol. 1999;127:95-6.

28. McGhee CN, Craig JP, Moseley H. Laser pointers can cause permanent retinal injury if used inappropriately. Br J Ophthalmol. 2000;84:229-30.

29. Smart D, Manson N, Marshall J, Mellerio J. New ocular hazard of mode locking in CW lasers. Nature. 1970;227:1149-50.

30. Sethi CS, Grey RH, Hart CD. Laser pointers revisited: a survey of 14 patients attending eye casualty at the Bristol Eye Hospital. Br J Ophthalmol. 1999;83:1164-7.

31. Barkana Y, Belkin M. Laser eye injuries. Surv Ophthalmol. 2000;44:459-78.

32. Wyrsch S, Baenninger PB, Schmid MK. Retinal injuries from a handheld laser pointer. N Engl J Med. 2010;363:1089-91.

33. U.S. FDA. Laser Toys: How to keep kids safe 2017. Available at, https://www.fda.gov/ForConsumers/ConsumerUpdates/ucm363908. htm. Accessed August 2, 2017.

34. U.S. FDA. Minimizing Risk for Children's Toy Laser Products 2014. Available at, https://www.fda.gov/downloads/medicaldevices/ deviceregulationandguidance/guidancedocuments/ucm363731.pdf. Accessed August 2, 2017.

35. Xu K, Chin EK, Quiram PK, Davies JB, Parke DW 3rd, Almeida DR. Retinal injury secondary to laser pointers in pediatric patients. Pediatrics. 2016;138:e2016188.

36. Hadler J, Tobares E, Dowell M Random testing reveals excessive power in commercial laser pointers. J. Laser Appl. 2013;25. https://lia.scitation.org/doi/10.2351/1.4798455.

37. Raoof N, Bradley P, Theodorou M, Moore AT, Michaelides M. The new pretender: a large UK case series of retinal injuries in children secondary to handheld lasers. Am J Ophthalmol. 2016;171:88-94.

38. Zhang L, Zheng A, Hie N, Bhavsar KV, Xu Y, Sliney DH, et al. Laser-induced photic injury phenocopies macular dystrophy. Ophthalmic Genet. 2016;37:59-67.

39. Birtel J, Harmening WM, Krohne TU, Holz FG, Charbel Issa P, Herrmann P. Retinal injury following laser pointer exposure - a systematic review and case series. Dtsch Arztebl Int. 2017; 114:831-7.

40. Lally DR, Duker JS. Foveal injury from a red laser pointer. JAMA Ophthalmol. 2014;132:297.

41. Zhao N, Liu L. Long-term changes in optic coherence tomography in a child with laser pointer maculopathy: a case report and mini review. Photo Photodyn Ther. 2017;18:264-6. 
42. Raoof N, Chan TK, Rogers NK, Abdullah W, Haq I, Kelly SP, et al. 'Toy' laser macular burns in children. Eye (Lond). 2014;28:231-4.

43. Alsulaiman SM, Alrushood AA, Almasaud J, Alkharashi AS, Alzahrani Y, Abboud EB, et al. Full-thickness macular hole secondary to high-power handheld blue laser: natural history and management outcomes. Am J Ophthalmol. 2015;160:107-13.e1.

44. Alsulaiman SM, Alrushood AA, Almadaud J, Alzaaidi S, Alsahrani Y, Arevalo JF, et al. High-power handheld blue laser-induced maculopathy: the results of the King Khaled Eye Specialist Hospital collaborative retina study group. Ophthalmology. 2014;121:566-72.e1.

45. Bhavsar KV, Wilson D, Margolis R, Judson P, Barbazetto I, Freund $\mathrm{KB}$, et al. Multimodal imaging in handheld laser-induced maculopathy. Am J Ophthalmol. 2015;159:227-31.e2.

46. Lee GD, Baumal CR, Lally D, Pitcher JD, Vander J, Duker JS. Retinal injury after inadvertent handheld laser exposure. Retina. 2014;34:2388-96.

47. Yiu G, Itty S, Toth CA. Ocular safety of recreational lasers. JAMA Ophthalmol. 2014;132:245-6.

48. Fujinami K, Yokoi T, Hiraoka M, Nishina S, Azuma N. Choroidal neovascularization in a child following laser pointer-induced macular injury. Jpn J Ophthalmol. 2010;54:631-3.

49. Lim ME, Suelzer J, Moorthy RS, Vemuri G. Thermal macular injury from a $154 \mathrm{~mW}$ green laser pointer. J AAPOS. 2014;18:612-4.

50. Dirani A, Chelala E, Fadlallah A, Antonios R, Cherfan G. Bilateral macular injury from a green laser pointer. Clin Ophthalmol. 2013;7:2127-30.

51. Dhoot DS, Xu D, Srivastava S. High-powered laser pointer injury resulting in macular hole formation. J Pediatr. 2014;164:668.e1.

52. Ziahosseini K, Doris JP, Turner GS. Laser eye injuries. Maculopathy from handheld green diode laser pointer. BMJ. 2010; 340:c2982.
53. Petrou P, Patwary S, Banerjee PJ, Kirkby GR. Bilateral macular hole from a handheld laser pointer. Lancet. 2014;383:1780.

54. Sell CH, Bryan JS. Maculopathy from handheld diode laser pointer. Arch Ophthalmol. 1999;117:1557-8.

55. Turaka K, Bryan JS, Gordon AJ, Redd Y, Kwong HM, Sell CH. Laser pointer induced macular damage: case report and mini review. Int Ophthalmol. 2012;32:293-7.

56. Simonett JM, Scarinci F, Labriola LT, Jampol LM, Goldstein DA, Fawzi AA. A case of recurrent, self-inflicted handheld lader retinopathy. JAAPOS. 2016;20:168-70.

57. Ueda T, Kurihara I, Koide R. A case of retinal light damage by green laser pointer (Class 3b). Jpn J Ophthalmol. 2011;55:428-30.

58. Hossein M, Bonyadi J, Soheilian R, Soheilian M, Peyman GA. SD-OCT features of laser pointer maculopathy before and after systemic corticosteroid therapy. Ophthalmic Surg Lasers Imaging. 2011;42:e135-8.

59. Ayalasomayajula SP, Ashton P, Kompella UB. Fluocinolone inhibits VEGF expression via glucocorticoid reception in human retinal pigment epithelial (ARPE-19) cells and TNF-alphainduced angiogenesis in chick chorioallantoic membrane (CAM). J Ocul Pharmacol Ther. 2009;25:97-103.

60. Stanbury RM, Graham EM. Systemic corticosteroid therapy-side effects and their management. Br J Ophthalmol. 1998;82:704-8.

61. Alassane S, Binquet C, Cottet V, Fleck O, Acar N, Daniel S, et al. Relationships of macular pigment optical density with plasma lutein, zeaxanthin, and diet in an elderly population: the Montrachet Study. Invest Ophthalmol Vis Sci. 2016; 57:1160-7.

62. Department for Business, Energy and Industrial Strategy. (August 2017). Call for evidence: laser pointers. Retrieved from https://www.gov.uk/government/uploads/system/uploads/a ttachment_data/file/637087/Call_for_Evidence_Lasers_PDF.pdf 